\title{
Mujeres y Universidad: situación actual y algunas propuestas para el cambio.
}

Women and University: current situation and some proposals for change.

Patricia Espejo Megías

Profesora Ayudante Doctora.

Área de Derecho del Trabajo y de la Seguridad Social.

Universidad de Castilla-La Mancha

E-mail: Patricia.Espejo@uclm.es

\section{Mujeres y Universidad: situación actual y algunas propuestas para el cambio.}

Women and University: current situation and some proposals for change.

\section{INTRODUCCIÓN}

Que la Universidad Pública sea un ejemplo de institución progresista e igualitaria no debería ser por más tiempo una entelequia. El binomio 'mujeres y universidad' continúa siendo, en según qué aspectos, una pareja mal avenida. Los datos ponen de manifiesto cómo todavía existe una fuerte brecha de género en la pirámide jerárquica de la Universidad Pública Española. El techo de cristal al que se enfrentan las mujeres dentro de la organización de enseñanza superior es fuerte y notorio, a pesar de la equitativa presencia de mujeres y hombres entre el personal docente e investigador universitario y de los amplios beneficios que diferentes estudios destacan en relación con la pluralidad de género en los órganos de dirección empresariales.

Naturalmente, la baja representación de las mujeres en los órganos de gobierno de las Universidades no es anecdótica; también se produce en las empresas privadas, en el ámbito político o en el sindical, entre otros. Y, aunque asistimos a un proceso paulatino de ciertas mejoras en materia de igualdad, también dentro de la carrera universitaria, la tendencia principal no es otra que aumentar los porcentajes de participación de las mujeres en los órganos de gobierno académicos sin que recaigan en ellas los puestos 
decisivos, esto es, los de mayor peso e influencia. Ergo, además de baja, la representación de la mujer en los órganos de gobierno de la Universidad pública aparece claramente sesgada y dirigida a cumplir el estereotipo tradicionalmente atribuido a la mujer, es decir, educación, cultura o cooperación.

Las mujeres universitarias han demostrado sobradamente su formación, independencia y capacidad de liderazgo, pero la segregación horizontal y vertical es una realidad incuestionable. Por ello, plantear que esta situación obedezca a una mayor capacidad intelectual de los hombres, como han defendido algunas corrientes de pensamiento a lo largo de la historia ${ }^{1}$, es una tesis que ha de ser definitivamente desechada. El mantenimiento del varón en las esferas de decisión y poder parece responder a una problemática mucho más profunda, esto es, a una estructura vital diseñada a medida de los hombres donde las trabajadoras, también las profesoras universitarias, deben recorrer el camino sorteando todo tipo de obstáculos y trabas ${ }^{2}$.

La Ley Orgánica 4/2007 de 12 de abril, por la que se modifica la Ley Orgánica 6/2001, de 21 de diciembre, de Universidad (en adelante, LOU), de conformidad con el art 9.1 de la Constitución Española, reconoce expresamente que los poderes públicos deben remover todos los obstáculos que impidan a las mujeres alcanzar una presencia en los órganos de gobierno de las universidades y en el nivel más elevado de la función pública docente e investigadora. En este sentido, aclara que esta presencia femenina debe ser acorde con el porcentaje que representan entre los licenciados/as universitarios/as, no debiendo soslayar la realidad española, donde más del $60 \%$ de las personas egresadas en grados, postgrados y másteres tienen rostro de mujer.

La LOU modifica el contenido del art. 13 de la anterior ley de universidades del año 2001 que se ocupa precisamente de los órganos de gobierno y representación de las universidades públicas. El nuevo artículo establece de forma expresa el deber de las universidades de fijar en sus estatutos un procedimiento electoral que permita una

\footnotetext{
${ }^{1}$ Son muchos los estudios acerca del liderazgo desde una perspectiva de género. Hay autores que han llegado a afirmar que son las propias mujeres quienes son excluyentes con ellas mismas frente a los cargos de poder al seguir estereotipos que les impiden romper las barreras y aceptar nuevos retos (Santos, 2000). Incluso, hay autores que se han atrevido a argüir que la causa principal de la falta de leadership femenina no es otra que las mujeres no poseen ni las características ni las motivaciones necesarias para llegar a un cargo de dirección y que por esta razón no se imaginan siendo exitosas, a diferencia de los hombres (Moncayo, 2013). Naturalmente que esta autora discrepa de forma rotunda con estas afirmaciones, basadas más en un criterio androcéntrico de lo que sucede en las entrañas del marco laboral que en una opinión fundamentada empíricamente de acuerdo con las estadísticas oficiales existentes en este sentido.

${ }^{2}$ Véase un análisis detallado de la problemática del techo de cristal en: ESPEJO MEGIAS, P., Hacia una reformulación de la violencia de género laboral, Wolters Kluwer, 2018.
} 
presencia equilibrada entre mujeres y hombres en los órganos colegiados. Respecto del requisito de que exista una presencia equilibrada, la disposición adicional primera de la Ley Orgánica 3/2007, de 22 de marzo, de Igualdad Efectiva entre Mujeres y Hombres (en lo sucesivo, LOIEMH) establece que será "la presencia de mujeres y hombres de forma que, en el conjunto a que se refiera, las personas de cada género no superen el sesenta por ciento ni sean menos del cuarenta por ciento".

Así, el art. 13 LOU aspira a corregir la desigualdad que desde una perspectiva de género se despliega en relación con el procedimiento electoral diseñado para conformar los órganos colegiados universitarios, a saber, el consejo social, el consejo de gobierno, el claustro universitario, la junta de facultad y el consejo de departamento. Este hecho no puede, sin embargo, hacernos pensar que no existe discriminación por razón de género en el trazado y desarrollo de las candidaturas y subsiguiente votación de los puestos de carácter unipersonal en la universidad. El porcentaje de rectoras, vicerrectoras, secretarias generales, gerentes, decanas y vicedecanas evidencia que el problema no reside solo en una infrarrepresentación femenina en los órganos de naturaleza plural, sino que abarca un espectro más amplio del que no escapan los órganos unipersonales.

El análisis de la segregación ocupacional en este sector de actividad resulta con todo complejo, en tanto en cuanto, en el tipo de participación de las mujeres en la universidad pública hay que tener en cuenta, entre otras cuestiones, tanto el plano gestor como el docente/investigador. En este orden de consideraciones, el propósito de este artículo no es otro que tratar de clarificar las luces y sombras de la presencia femenina en este ámbito mostrando la situación actual de las universidades públicas españolas, a partir de una selección de diferentes universidades con distintas estructuras de liderazgo que permita elaborar un estudio comparado más detallado.

\section{EL GOBIERNO DE LAS UNIVERSIDADES: UN TERRITORIO MASCULINIZADO}

Como decía, para conocer la situación del liderazgo femenino en el ámbito de la educación superior en España es recomendable analizar, en primer lugar, cuál es el porcentaje de mujeres al frente de los órganos de gobierno de las universidades. En este sentido, las estadísticas evidencian una leve tendencia a la equidad de género en el seno de los órganos unipersonales en la última década. No obstante, en todos los casos continúa siendo superior el número de hombres que el de mujeres. La Universidad Pública Española cuenta con un 26 por ciento de directoras de departamento, un 27 por 
ciento de decanas, un 39 por ciento de vicerrectoras y tan solo un 18 por ciento de rectoras. Los vicedecanatos constituyen el único ejemplo dónde la aproximación entre mujeres y hombres es significativa (53 por ciento de varones frente a un 47 por ciento de mujeres).

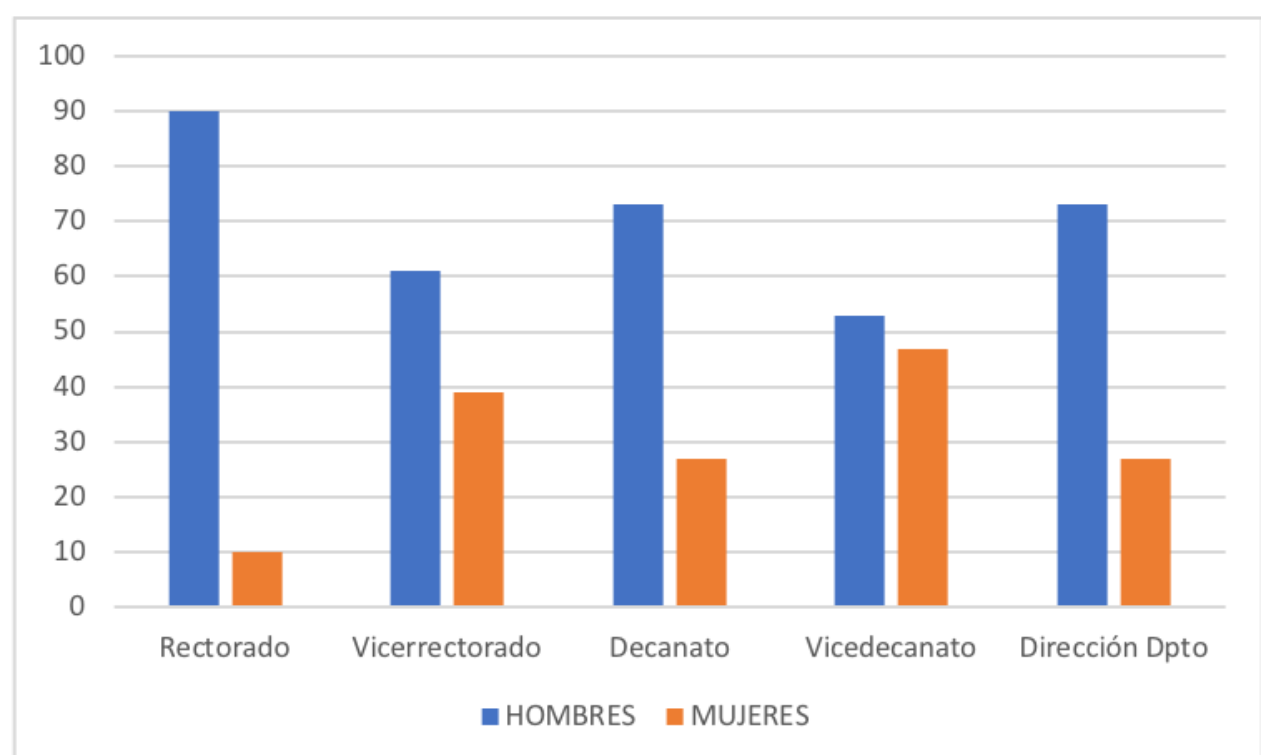

Gráfico 1: Puestos de dirección y de toma de decisiones en la universidad pública española por sexo

Fuente: elaboración propia

Probablemente los dos órganos de gobierno más representativos sean los rectorados y los decanatos, órganos ambos de carácter unipersonal que, como veíamos, quedan fuera del artículo 13 LOU. De ellos, el primero es sin duda el que muestra una foto más real de la falta de presencia de las mujeres en la gestión y administración de los centros universitarios. El número de rectoras en nuestro país ha aumentado en ocho puntos en el último año, pasando del 10 por ciento en 2018 al 18 por ciento en 2019. Estos datos muestran una realidad alejada todavía de ser proporcional al número de mujeres y hombres que prestan sus servicios en este sector y que tienen currículums y acreditaciones del más alto nivel. Actualmente, son nueve las mujeres que desempeñan este cargo en España de un total de 50 universidades públicas. 


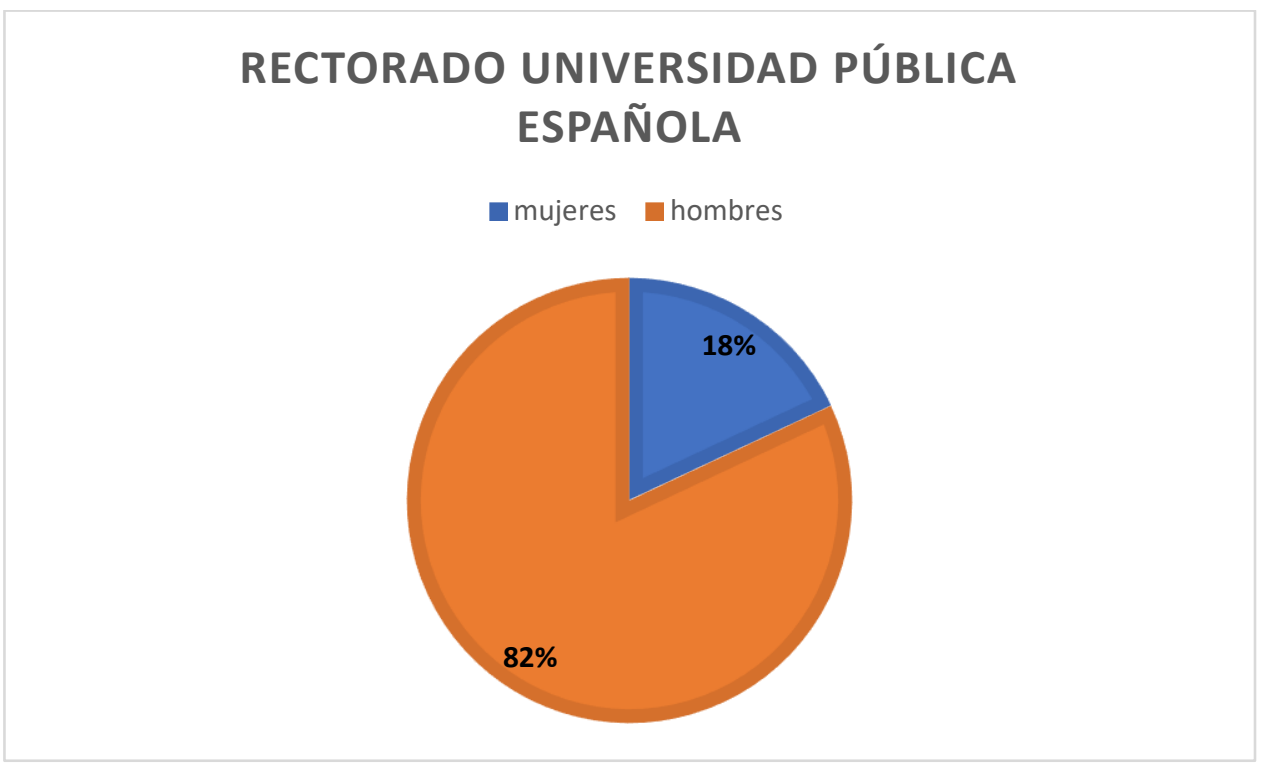

Gráfico 2: Números de mujeres y hombres al frente de los Rectorados

Fuente: elaboración propia

Si nos detenemos a analizar el liderazgo femenino en los puestos de mando en las universidades objeto de este estudio, comprobamos cómo las estadísticas siguen la tendencia del gráfico descrito, que no es sino una media aritmética de lo que sucede en cada uno de los centros públicos de enseñanza superior del país.

En la Universidad de Castilla-La Mancha, la presencia masculina es sensiblemente mayor en los órganos unipersonales de gobierno. A la cabeza del Rectorado está un hombre, pero no solo eso. Nunca, en los treinta y tres años de vida de la Universidad de Castilla-La Mancha ${ }^{3}$, ha habido una mujer rectora. El puesto de Gerente y el de Secretario General también son ocupados por varones. Asimismo, es también un varón el que se encuentra al frente de la Defensoría del estudiante en la Universidad de Castilla-La Mancha. Ninguno de estos tres puestos ha sido ocupado por una mujer en estas tres décadas de historia.

Afortunadamente, la Universidad de Castilla-La Mancha ofrece un dato positivo en relación con el empoderamiento de las mujeres y el gobierno de la institución; la representación de quienes encabezan los vicerrectorados tiene, por primera vez en la historia de esta universidad, un rostro mayoritariamente femenino (5 vicerrectoras frente a 3 vicerrectores). Ahora bien, sin ánimo de restar importancia al dato cuantitativo, no

\footnotetext{
${ }^{3}$ La Universidad de Castilla-La Mancha comenzó su andadura en el año 1985, aunque formalmente se creó mediante la Ley de 30 de junio de 1982, como resultado de la autonomía política y del deseo colectivo manifestado por la sociedad castellano-manchega y compartido por el Gobierno regional.
} 
podemos dejar pasar por alto una cuestión; las tres áreas más relevantes dentro de la dirección de la universidad, a saber, la economía y la planificación, la investigación y la política científica y los asuntos relacionados con el profesorado coinciden precisamente con los tres vicerrectorados que en Castilla-La Mancha están liderados por hombres. Estos datos demuestran que, tal y como avanzábamos al inicio de este trabajo, la presencia de la mujer en los puestos de mando dentro de la universidad pública aparece sesgada y responde al estereotipo que tradicionalmente se le ha atribuido al género femenino ${ }^{4}$.

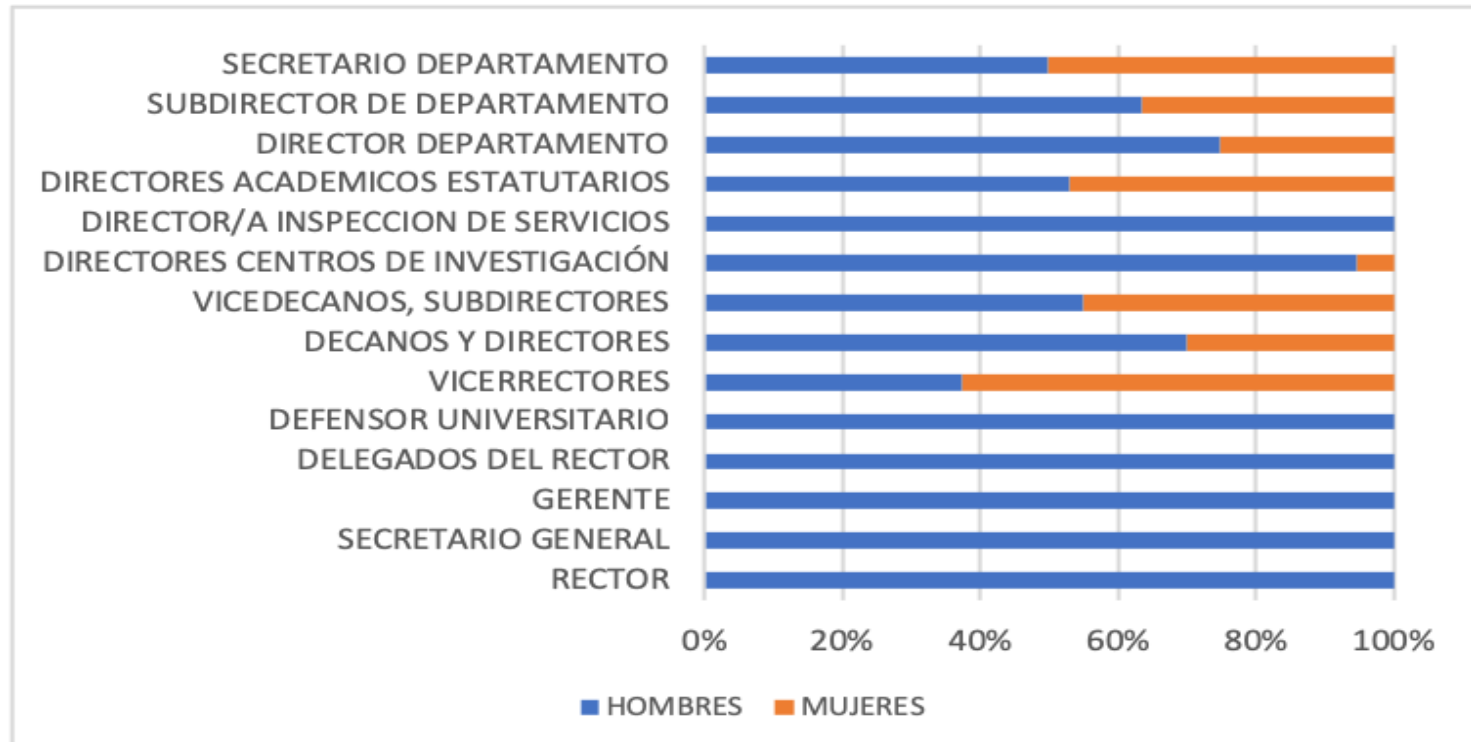

Gráfico 3: Puestos unipersonales de dirección y toma de decisión en la Universidad de Castilla-La Mancha por sexo

Fuente: elaboración propia

Asimismo, los hombres son una clara mayoría en los órganos de gobierno colegiados y en la mayor parte de las comisiones. Cabe destacar la baja presencia femenina en el Consejo Social, órgano colegiado de participación de la sociedad castellanomanchega en el gobierno y administración de dicha Universidad y cauce permanente de diálogo y comunicación entre estos y el Gobierno de la Región. De un total de 21 miembros, solo tres son mujeres y ninguna de ellas ocupa un puesto destacado dentro de este organismo (presidencia, vicepresidencia o secretaría) ${ }^{5}$.

En este sentido, hay que saber que quien nombra a la persona titular de la presidencia del Consejo Social es el Consejo de Gobierno de la Junta de Comunidades de Castilla-

\footnotetext{
${ }^{4}$ ACKER, S., Género y educación. Reflexiones sociológicas sobre mujeres, enseñanza y feminismo, Narcea, 1995.

${ }^{5}$ http://blog.uclm.es/consejosocial/pleno/
} 
PATRICIA ESPEJO MEGÍAS Mujeres y Universidad: situación actual y algunas propuestas para el cambio.

La Mancha, a propuesta de la persona titular de la Consejería competente en materia de enseñanza universitaria, de entre personas de reconocido prestigio en los ámbitos científico, técnico, cultural, artístico, profesional, social o económico. Que este, a su vez, nombrará tanto al Vicepresidente o Vicepresidenta, de entre los miembros que representan los intereses sociales, como al Secretario o Secretaria, persona que deberá acreditar estar en posesión de una titulación universitaria superior y contar con una notoria experiencia en la gestión de entidades públicas o privadas,

Resulta asombroso que ningún gobierno en esta comunidad autónoma haya pensado en una mujer como persona con méritos y capacidades suficientes para estar al frente de la presidencia del Consejo Social. En esta misma línea argumental, sorprende que los varones nombrados para liderar este órgano tampoco hayan encontrado a ninguna mujer con válidas aptitudes para ocupar los puestos de vicepresidencias o secretarias. La razón de esta situación apunta, a todas luces, a una subordiscriminación sistémica y endémica hacia las mujeres, de la que no escapa la universidad pública 6 .

En la Universidad de Murcia, el panorama no es mucho mejor que el descrito en Castilla-La Mancha. Tampoco el cargo de rector ha sido nunca desempeñado por una mujer. Los puestos que abrazan al rector se hallan asimismo absolutamente masculinizados y únicamente en la representación de los vicerrectorados encontramos la paridad, con 6 vicerrectoras y 6 vicerrectores.

\footnotetext{
${ }^{6}$ BARRÈRE UNZUETA, María Ángeles, Derecho antidiscriminatorio y acción positiva en favor de las
} mujeres, Civitas, 1997. 
PATRICIA ESPEJO MEGÍAS Mujeres y Universidad: situación actual y algunas propuestas para el cambio.

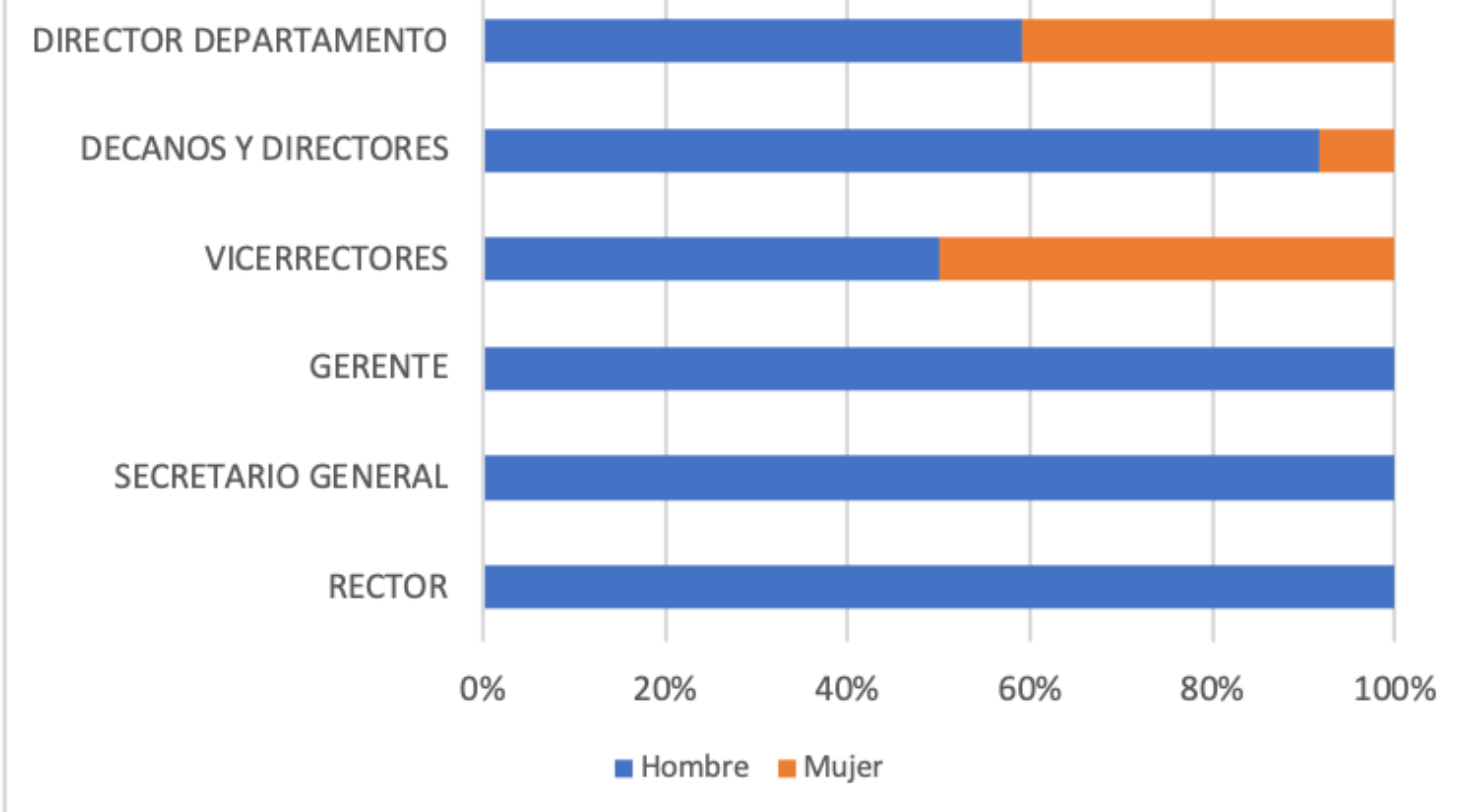

Gráfico 4: Puestos unipersonales de dirección y toma de decisión en la Universidad de Murcia por sexo Fuente: elaboración propia

Por último, la Universidad de Huelva ofrece un escenario distinto si tenemos en cuenta que al mando del equipo de gobierno hay una mujer desde julio de $2017^{7}$. Este hecho supone per se un viraje significativo en la situación de la mujer la cúspide de la pirámide organizativa de esta institución. Por primera vez en su historia, la universidad onubense cuenta con una rectora, una gerente y una defensora de los y las estudiantes, tres de los puestos más importantes dentro del organigrama de la universidad española.

El gráfico nos muestra cómo el color naranja gana terreno en esta ocasión en aquellos puestos de mayor prestigio, liderazgo y responsabilidad, un hecho que ha originado transformaciones de calado dentro de la universidad onubense. No solo ha aumentado el número de mujeres al mando de los diferentes vicerrectorados desde el nombramiento de una mujer como rectora; los cambios que han experimentado algunos de ellos son fundamentales en materia de igualdad desde una perspectiva de género.

Entre ellos, el más significativo es, a mi entender, el cambio de nombre y, con él, de competencias, del Vicerrectorado de Planificación Estratégica, que pasa a llamarse

\footnotetext{
${ }^{7}$ La autora del presente trabajo realizó una estancia de investigación desde el 1 al 31 de julio de 2017 en la Universidad de Murcia y otra desde el 1 al 31 de junio de 2018 en la Universidad de Huelva, esta última con el objetivo de analizar precisamente los resultados obtenidos tras el nombramiento María Antonia Peña como rectora y de Cinta Martos como directora de una unidad de igualdad de dicha institución el 11 de julio de 2017.
} 
PATRICIA ESPEJO MEGÍAS Mujeres y Universidad: situación actual y algunas propuestas para el cambio.

Vicerrectorado de Planificación Estratégica, Calidad e Igualdad. Se trata del vicerrectorado más transversal por lo que es especialmente importante que la temática de igualdad haya sido incluida en su seno. Este hecho marcha una diferencia fundamental en la forma de entender el principio de igualdad de trato y de oportunidades en esta institución. La igualdad no puede quedar en un compartimento estanco sino que debe ser una materia que interrelacione todos y cada uno de los vicerrectorados y de los asuntos que en ellos se aborden.

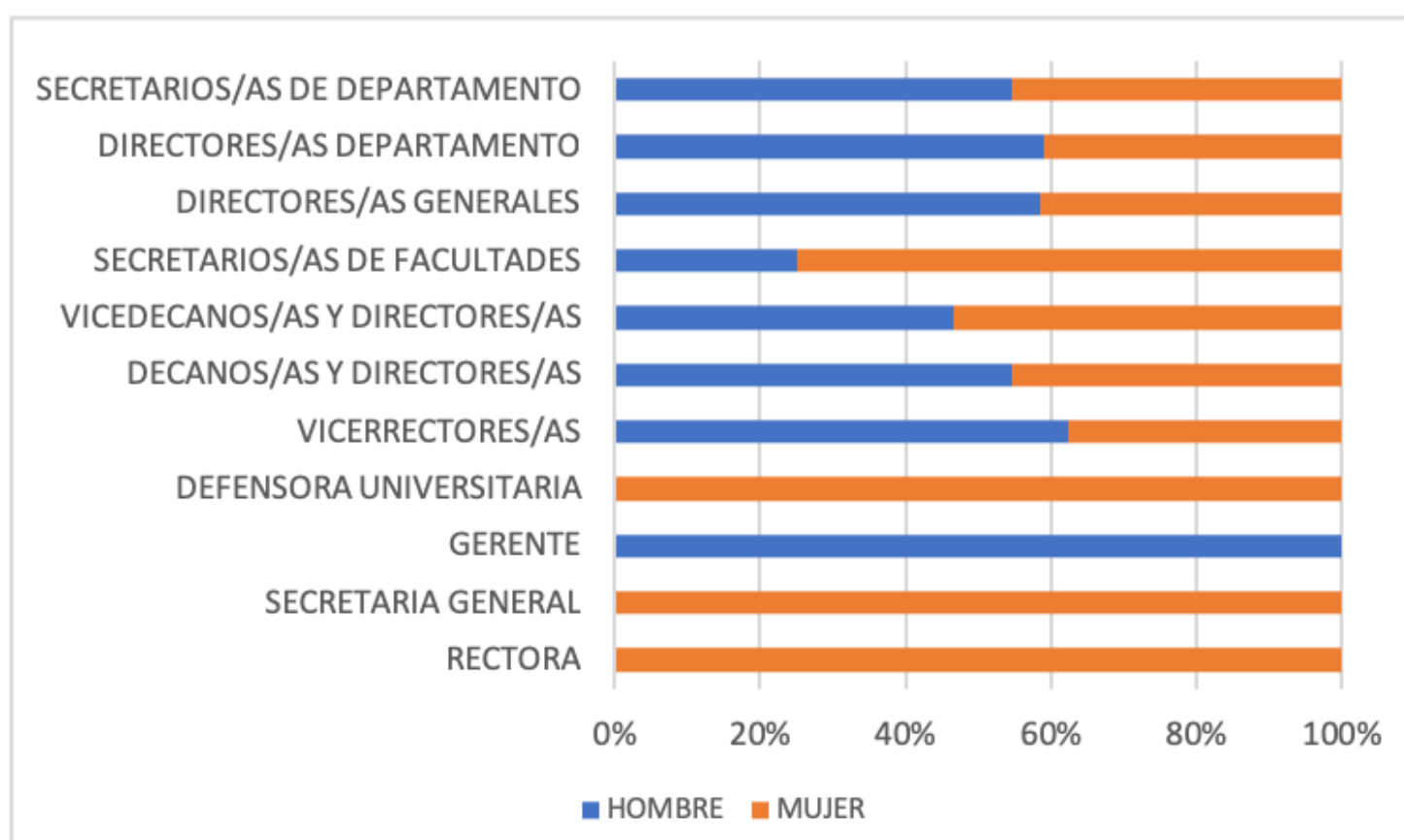

Gráfico 5: Puestos unipersonales de dirección y toma de decisión en la Universidad de Huelva por sexo Fuente: elaboración propia

\section{CARRERA DOCENTE E INVESTIGADORA EN CLAVE DE GÉNERO}

El apartado cuarto del art. 41 LOU establece que las universidades promoverán que los equipos de investigación desarrollen su carrera profesional fomentando una presencia equilibrada de mujeres y hombres en todos sus ámbitos.

Aparentemente, el precepto no hace más que exhortar a las universidades la paridad en su personal docente e investigador; sin embargo, el término "promoverán" que utiliza el art. 41 LOU sugiere una acción, una obligación de hacer todo lo que sea posible para que suceda lo que se expresa. Asimismo, el tiempo verbal futuro simple se traduce en un deber legal que exige una actuación contundente por parte de las universidades orientada a fomentar la igualdad de oportunidades entre el PDI femenino y masculino y 
su promoción profesional. No basta con la intención, se requiere un resultado y, por el momento, no se está produciendo el resultado deseado.

Las estadísticas evidencian cómo el número de mujeres y hombres que conforman el profesorado de las universidades es prácticamente coincidente. Como avanzábamos en la introducción, el estudio se centra en el análisis de tres universidades, muestra, a mi entender, suficiente para demostrar lo que sucede, en términos generales, en el ámbito de la educación superior de nuestro país. En todas ellas, el porcentaje de mujeres profesoras supera el 40 por ciento (el 41 en Castilla-La Mancha y el 43 en Murcia y en Huelva). Sin embargo, esta presencia femenina en las universidades españolas no se corresponde con el bajo número de catedráticas (Gráfico 9) ni tampoco con el porcentaje de mujeres en cargos de responsabilidad y liderazgo dentro del gobierno de las universidades y de los equipos decanales que dirigen las diferentes facultades del país (Gráfico 2).

La presencia equilibrada a la que hace alusión el art. 41 LOU, es decir, una presencia de mujeres y hombres en todos los ámbitos de la universidad, no ocurre más allá de estas letras. Si analizamos los distintos niveles profesionales dentro de las universidades pronto vemos cómo la presencia de mujer se concentra masivamente en algunos de ellos. El profesorado femenino aparece fundamentalmente en las figuras contractuales de la base de la pirámide universitaria, a saber, ayudante, ayudante doctor y contratado doctor. También observamos cómo las mujeres son, a menudo, contratadas como profesoras colaboradoras, asociadas o sustitutas interinas. Ergo, las mujeres son minoría en las categorías de la Función Pública dentro de la enseñanza docente superior.

En la Universidad de Castilla-La Mancha hay un total de 38 mujeres catedráticas frente a 176 catedráticos (sumando el profesorado catedrático de escuela universitaria y de universidad) y 271 profesoras titulares frente a 410 profesores titulares (sumando, de nuevo, el profesorado titular de escuela universitaria y de universidad). Al bajar a la figura del profesor contratado doctor (interino y neto), el número de mujeres y hombres comienza a aproximarse. Así, en la UCLM, hay 215 profesoras contratadas doctoras y 252 profesores contratados doctores (sumando los contratos temporales y los indefinidos). Las mujeres solo superan a los hombres al descender hasta la figura del profesor ayudante doctor (36 mujeres frente a 31 varones) quedando ambos sexos casi parejos en la figura del ayudante (21 mujeres y 30 hombres). 


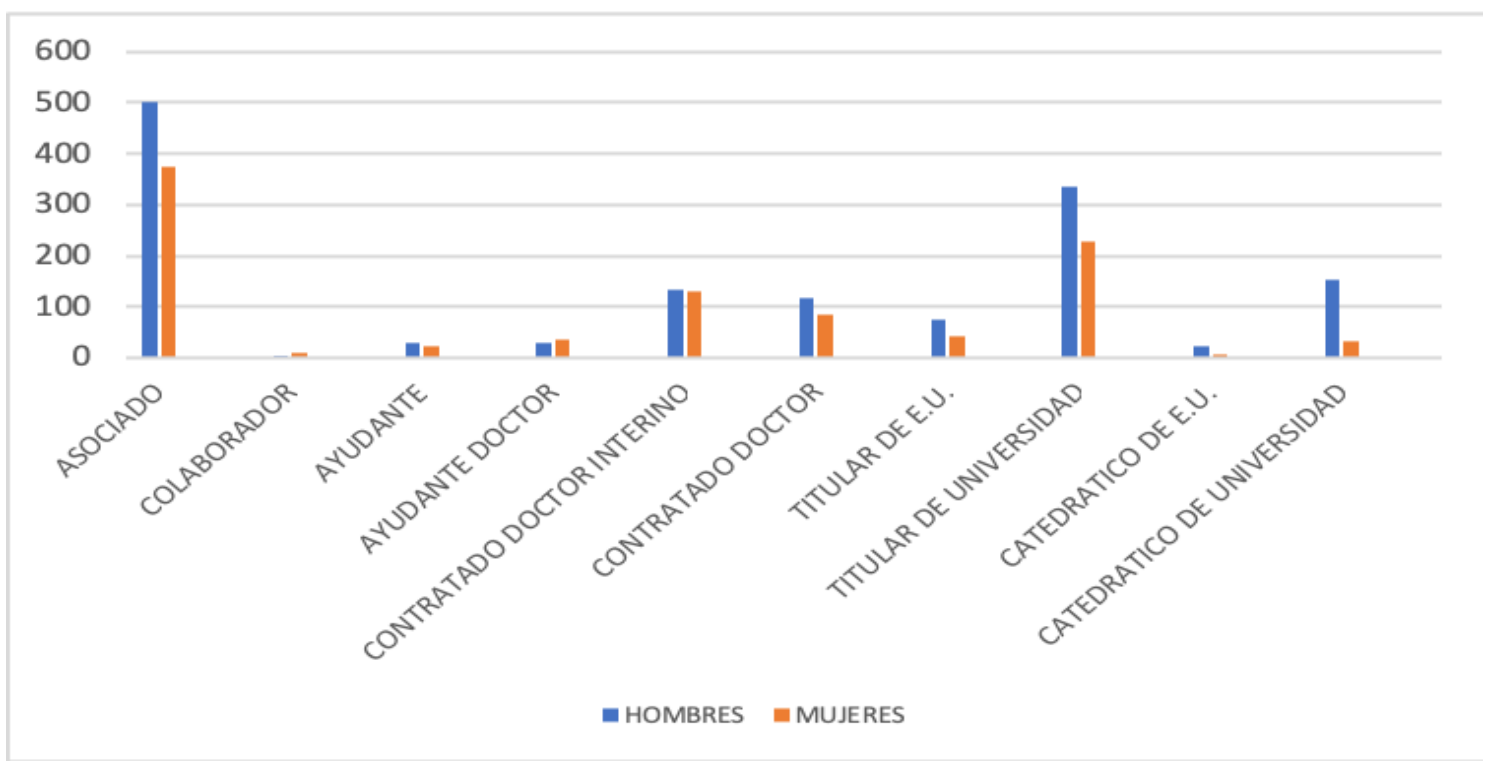

Gráfico 6: PDI de la Universidad de Castilla-La Mancha por nivel profesional y sexo

Fuente: elaboración propia

La Universidad de Murcia, por su parte, cuenta con 97 catedráticas frente a 176 catedráticos (sumando el profesorado catedrático de escuela universitaria y de universidad) y con 315 profesoras titulares frente a 442 profesores titulares (sumando el profesorado titular de escuela universitaria, de universidad y vinculado). Las mujeres son mayoría entre el profesorado contratado doctor (159 mujeres frente a 119 hombres) y el número de mujeres y de hombres se iguala por completo al descender a las figuras de ayudante doctor (26 mujeres y 26 varones) y de profesor sustituto interino (19 mujeres y 19 hombres). Ergo, en el caso de Murcia, de nuevo, las profesoras se concentran en la base de la pirámide. 


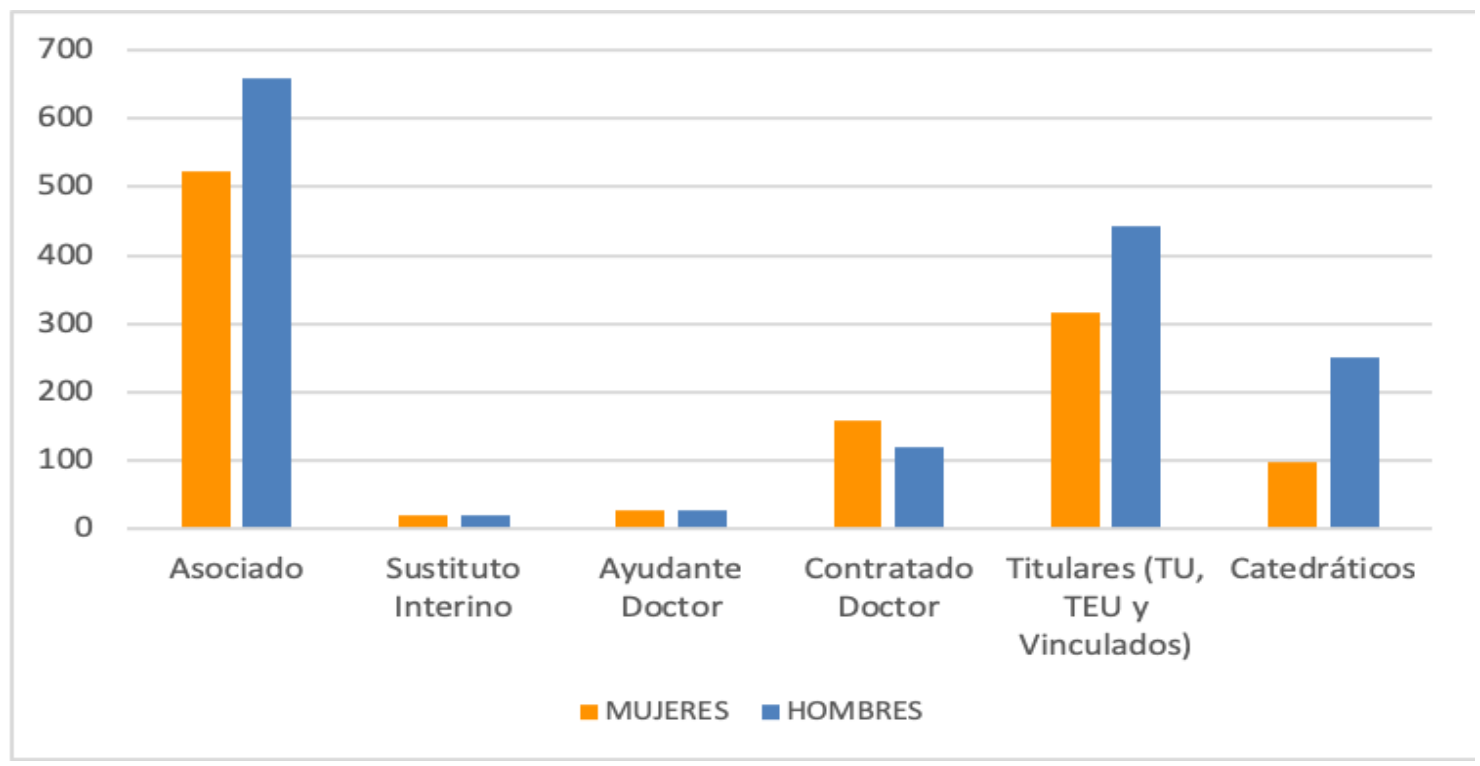

Gráfico 7: PDI de la Universidad de Murcia por nivel profesional y sexo

Fuente: elaboración propia

Conviene aclarar que la figura del profesor sustituto interino, conocida por sus siglas PSI, no se contempla en la actualidad en la Universidad de Castilla-La Mancha pero sí es muy común en otras universidades, donde se ha extendido exponencialmente su uso. La normativa de algunas universidades, como la de Murcia o las universidades andaluzas, entre ellas, la de Huelva, han regulado el procedimiento por el cual se podrá dar cobertura a las "necesidades docentes urgentes, inaplazables, y sobrevenidas de carácter temporal que den lugar a la sustitución del profesorado con la asignación del respectivo encargo docente".

En el caso de la Universidad de Murcia, es una modalidad de contratación temporal utilizada para cubrir las situaciones de incapacidad temporal por accidentes $\mathrm{u}$ enfermedades, las licencias de maternidad o paternidad, las excedencias o las vacantes ${ }^{8}$. La negociación colectiva también aborda esta cuestión; el art. 25 del II Convenio colectivo del Personal Docente e Investigador contratado laboral de las universidades públicas de la Comunidad Autónoma de la Región de Murcia establece los requisitos que deben cumplirse para que este tipo de contratación se ajuste a lo preceptuado en el art. 15.1. c) del Estatuto de los Trabajadores y en su normativa de desarrollo.

\footnotetext{
${ }^{8}$ Resolución del Rector de la Universidad de Murcia (R-589/2018) de fecha 1 de junio de 2018, por la que se convoca concurso público de méritos, para la constitución de bolsas de empleo para la contratación de personal docente de sustitución.
} 
En el caso de la Universidad de Huelva, serán causas de sustitución en las tareas docentes determinadas en el Plan de Organización Docente de cada curso académico, las que se originen a partir de bajas laborales, excedencias, licencias reconocidas, funciones de representación de los trabajadores, reducción por cargos académicos estatutarios o asimilados $^{9}$, de conformidad con el art. 2 del Reglamento de Procedimiento para la Contratación de Profesorado Sustituto Interino en la Universidad de Huelva de $2014^{10}$. El Vicerrectorado de Ordenacion Académica y Profesorado de la Universidad de Huelva publica al inicio de cada curso académico una Instrucción donde establece el procedimiento de constitución de las bolsas de trabajo del Profesorado Sustituto Interino. Este tipo de contratación, ideado para dar cobertura temporal a los puestos de trabajo objeto de selección, tiene como objetivo "evitar que el alumnado no reciba docencia", debiéndose hacer dicha selección según lo dispuesto en el citado Reglamento y en el RD 2720/1998, de 18 de diciembre.

La Universidad de Huelva no muestra un panorama mejor que el de Castilla-La Mancha y Murcia en lo que se refiere a la situación contractual de su plantilla femenina. Las mujeres son más del doble que los hombres en las figuras más precarizadas, tales como el profesorado asociado, donde la institución cuenta con 90 mujeres y 37 varones.

Las profesoras onubenses son superadas por sus colegas masculinos en los niveles profesionales de mayor rango, esto es, el cuerpo de titulares y el de catedráticos. En ambos supuestos, el número de varones es significativamente superior al de mujeres. En el caso del profesorado titular (sumando el de escuela universitaria y el de universidad), la Universidad de Huelva cuenta con 118 mujeres y con 190 varones. La plantilla de profesores catedráticos asciende a 82 , siendo solo 12 las mujeres que ocupan una plaza de cátedra en la institución onubense.

Los números de mujeres y hombres no se igualan hasta descender a las categorías de contratado doctor (42 mujeres y 42 hombres), de ayudante (18 mujeres y 20 hombres) y de colaborador (32 mujeres y 32 hombres).

\footnotetext{
9 Sin embargo, no siempre la finalidad de este contrato es cubrir las situaciones descritas. En otras universidades andaluzas, como la de Málaga, es habitual que con este contrato se pretenda cubrir plazas de ayudante doctor que están pendientes de salir a concurso. En este caso, ocupan este puesto aquellos profesores o profesoras que se encuentran realizando su Tesis doctoral y que no han podido acceder a un contrato de ayudante.

${ }^{10}$ Aprobado en Consejo de Gobierno de 28 de noviembre de 2014.
} 


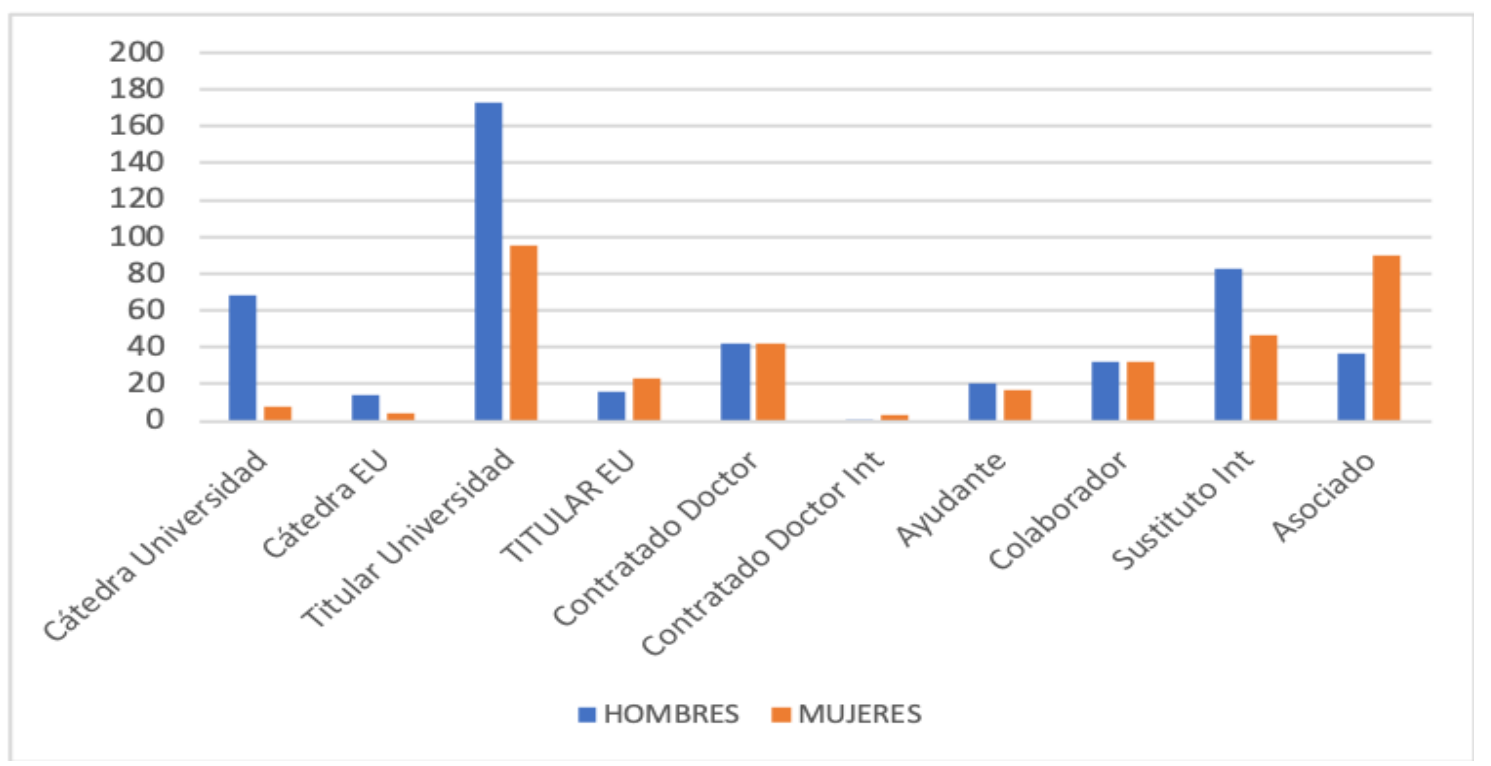

Gráfico 8: PDI de la Universidad de Huelva por nivel profesional y sexo

Fuente: elaboración propia

En este orden de consideraciones, es primordial tener en cuenta el art. 57.2 LOU, que se refiere a la acreditación nacional del personal docente e investigador. Y es que, la promoción del profesorado universitario se halla absolutamente condicionada a la evaluación que la Agencia Nacional de Evaluación de la Calidad y Acreditación (en adelante, ANECA) o, en algunos territorios y para determinados niveles profesionales, las agencias autonómicas hagan de su currículum. Lo que el apartado segundo del art. 57 viene a establecer no es otra cosa que la necesidad de desarrollo reglamentario de la composición, procedimiento de actuación y plazos para resolver de las comisiones evaluadoras.

La LOU manifiesta que la composición de estas comisiones debe atender a los criterios de imparcialidad y profesionalidad, "procurando", en todo caso, que sea equilibrada, desde una perspectiva de género, "salvo que no sea posible por razones fundadas y objetivas debidamente motivadas". A este respecto, conviene manifestar que el verbo procurar no parece ser el más adecuado habida cuenta de que es una norma con rango de ley la que establece esta exigencia. Tampoco resulta adecuado el último añadido, que no es sino una suerte de vía de escape al cumplimiento de deber legar que aquí se contempla. Además, nada se dice acerca de qué debe entenderse exactamente por "razones fundadas y objetivas" o sobre cómo pueden estar debidamente probadas, lo que provocará soluciones contradictorias entre quienes deban interpretar esta norma jurídica. 
Garantizar que las comisiones que evalúan los currículums del personal docente e investigador respeten la equidad de género es una forma de asegurar la imparcialidad de dichas comisiones en el examen de los conocimientos y méritos del profesorado universitario. Y es que a nadie extrañará que se afirme que la autoría de la investigación de género es sobre todo femenina o que el valor que se le otorga a la misma es menor que a otras cuestiones del saber. Por lo tanto, es fundamental que el análisis de las aportaciones científicas habidas en los currículums sometidos a la valoración de estos entes se haga por parte de catedráticos y catedráticas en términos de igualdad.

A nivel supranacional, la Asociación Europea para la Garantía de la Calidad de la Educación Superior (en lo sucesivo, ENQA) es el organismo de la Unión Europea del que forman parte las agencias de calidad de la educación superior de los Estados miembros. Naturalmente, para poder formar parte de ENQA, hay que cumplir con los denominados "ESG", por sus siglas en ingles" ${ }^{11}$. Los ESG no son sino un conjunto de criterios y directrices que han sido diseñados para garantizar la calidad de la enseñanza en el Espacio Europeo de Educación Superior (EEES). Estos estándares establecen una serie de aspectos a tener en cuenta por las agencias que, de ser cumplidos, garantizan un compromiso con la calidad, la transparencia, la independencia y la ética en el ámbito universitario.

Puede observarse una modificación significativa del contenido de los estándares europeos de calidad en la última década. Sin embargo, sorprende, que en el proceso de actualización de los ESG no se haya tenido en consideración ni la dimensión social ni el principio de igualdad ${ }^{12}$. Hay que tener presente que la obtención por parte de las agencias de evaluación de los sellos de calidad está condicionada al cumplimiento de los ESG y que, por el momento, la igualdad como derecho fundamental no es tenida en cuenta a la hora de conceder este distintivo a las agencias.

Es fundamental que desde Europa se valorice la investigación de género. En España, hay que destacar cómo la Agencia de Calidad y Prospectiva Universitaria de Aragón ${ }^{13}$ está llevando a cabo un proyecto basado en una mejor y mayor consideración de la temática de género en la calificación de los currículums del profesorado universitario.

\footnotetext{
${ }^{11}$ European Standards and Guidelines for Quality Assurance in the European Higher Education Area.

${ }^{12}$ Pueden consultarse en: https://enqa.eu/wp-content/uploads/2015/11/ESG_2015.pdf

${ }^{13}$ Conocida por su acrónimo ACPUA, la agencia de evaluación aragonesa es miembro de ENQA desde 2016.
} 
Dicho esto, es importante ahora detenernos en una cuestión; es el profesorado con cátedra, y de reconocido prestigio, el único que, según el art. 57.2 LOU, puede formar parte de las comisiones de evaluación de la calidad del PDI funcionario. La obtención de la cátedra otorga al profesor o profesora un estatus relevante y le permite liderar con mayor facilidad equipos de trabajo y otros proyectos docentes y de investigación. De hecho, la realidad nos muestra cómo los proyectos de investigación financiados, regionales, nacionales o europeos, se suelen conceder al profesorado que ha obtenido la acreditación favorable como profesor/a catedrático/a de universidad por parte de ANECA.

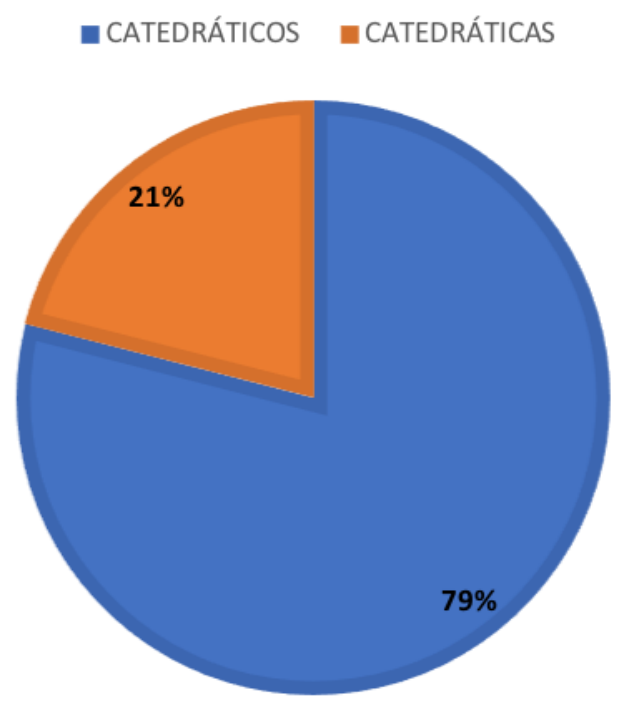

Gráfico 9: Porcentaje de cátedras españolas por sexo

Fuente: elaboración propia

Por esta razón, es un hecho clave obtener la acreditación a cátedra en términos de liderazgo. Podríamos pensar que este mayor número de concesiones a cátedra a los varones obedece a que en algunas áreas de conocimiento aparece el elemento "estereotipo" o, si se prefiere, la "brecha de género STEM"14. Dicho de otro modo, el menor porcentaje de cátedras a mujeres podría ser consecuencia del bajo número de mujeres en estas áreas de conocimiento o, incluso, alguien podría pensar que el PDI femenino cuenta con peores currículums. Nada más lejos de la realidad.

Si observamos el porcentaje del PDI acreditado a catedrático de universidad en el año 2018 vemos como es significativamente superior el número de hombres que de mujeres,

${ }^{14}$ Disciplinas de Ciencias, Tecnología, Ingeniería y Arquitectura y Matemáticas, según sus siglas en inglés. 
no apreciándose una diferencia notable entre el número de solicitudes presentadas a este nivel profesional desde una perspectiva de género. Los datos oficiales ponen de manifiesto cómo también en las disciplinas feminizadas del saber las cátedras son concedidas más a los hombres. En el año 2018, hasta la última resolución de fecha 18 de julio, han sido acreditadas a cátedra 34 mujeres y 63 hombres en la rama de Ciencias Sociales y Jurídicas (Gráfico 10), y 10 mujeres y 19 hombres en la rama de Humanidades (Gráfico 11) ${ }^{15}$.

Que las estadísticas demuestren que incluso en las disciplinas ocupadas por lo común por el profesorado femenino el número de varones acreditados a cátedra es siempre superior es la prueba de que la universidad queda lejos de ser una institución que promueva de forma efectiva la igualdad de trato y de oportunidades entre el profesorado de uno y otro sexo ${ }^{16}$.

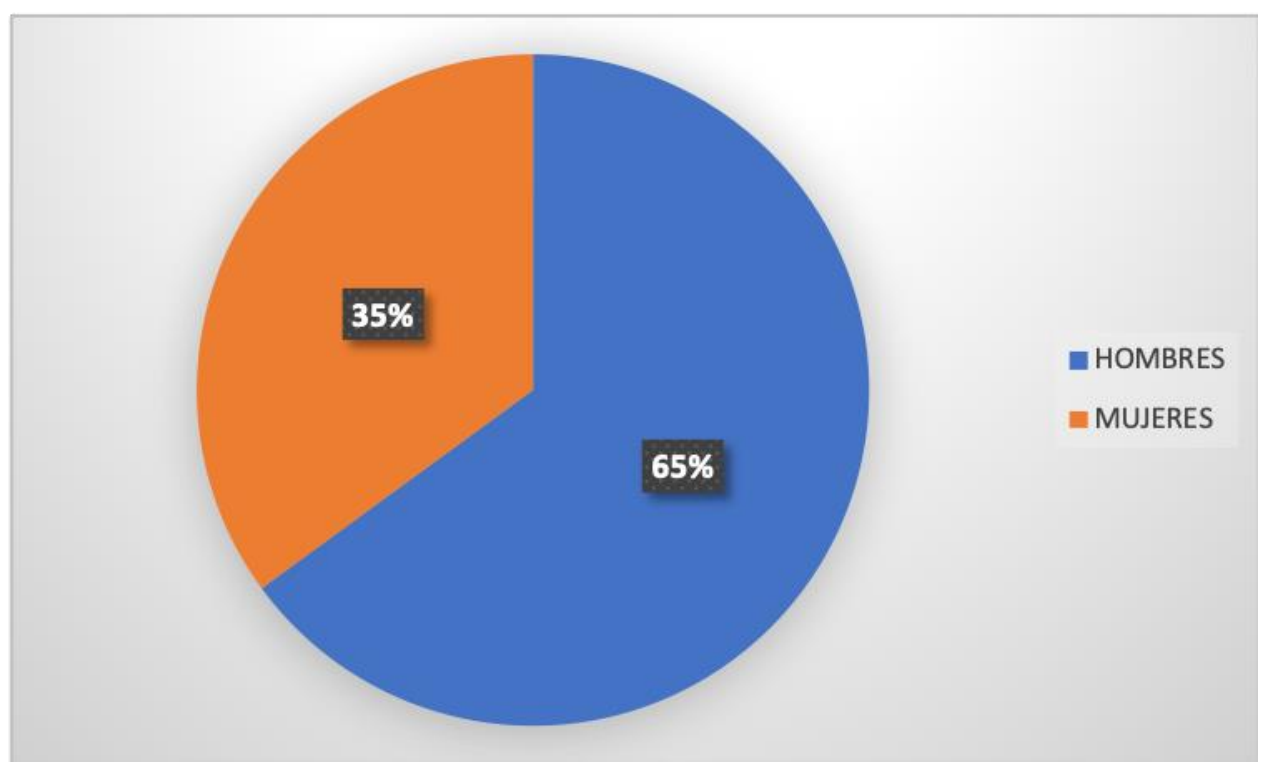

Gráfico 10: Porcentaje de cátedras concedidas por ANECA en el año 2018, por sexo, en la rama de Ciencias Sociales y Jurídicas

Fuente: elaboración propia

\footnotetext{
${ }^{15}$ http://www.aneca.es/Programas-de-evaluacion/Evaluacion-deprofesorado/ACADEMIA/Acreditaciones-concedidas en el año 2018.

${ }^{16}$ Sobre la necesidad de establecer medidas de acción positiva para corregir la situación disfuncional en este campo puede consultarse: ESPEJO MEGÍAS, Patricia, "La necesaria introducción de políticas de género en las universidades españolas", en AA.VV. (Coords. CASANOVA MARTÍ, Roser y VILLÓ TRAVÉ, Cristina) Nuevos retos docentes en ciencias sociales y jurídicas, Huygens, 2017, págs. 301-308.
} 


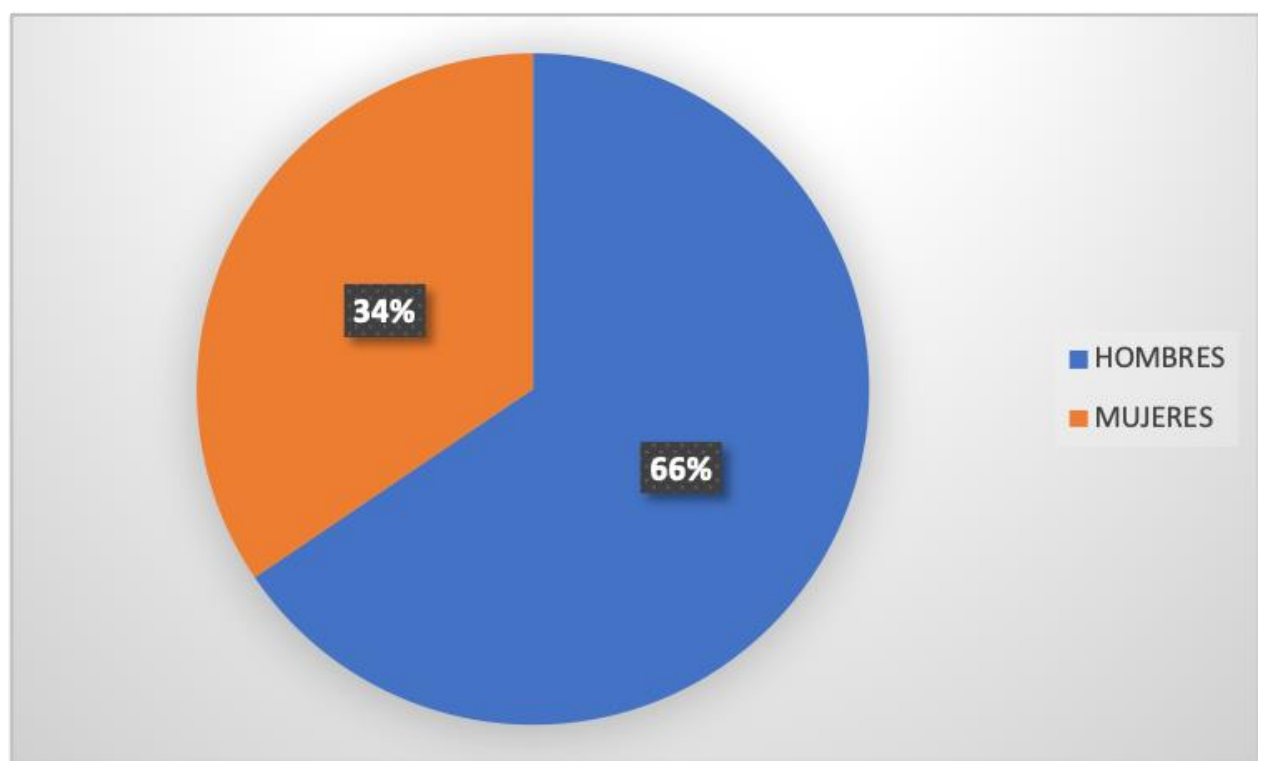

Gráfico 11: Porcentaje de cátedras concedidas por ANECA en el año 2018, por sexo, en la rama de Humanidades

Fuente: elaboración propia

El profesorado emérito es otra muestra más de cómo actúa la brecha de género en el ámbito de la educación superior de nuestro país. Llegado el momento de la jubilación, al personal docente e investigador que posea méritos relevantes por su historial académico y sus servicios destacados en la universidad durante, al menos, diez años se le puede conceder esta distinción. El art. 22 del Real Decreto 898/1985, de 30 de abril, sobre régimen del profesorado universitario (en adelante, RDRPU) establece que la declaración de profesor emérito implicará la constitución de una relación de empleo contractual que, sin embargo, quedará exenta del cumplimiento de las obligaciones que en materia de cotización establezcan las disposiciones del sistema de la Seguridad Social.

Como vemos, a través de esta figura, al profesorado universitario "por causa del mérito" se le otorga un tratamiento especial que se traduce, en definitiva, en una posición de liderazgo. Esto es así en tanto en cuanto, al profesor emérito se le concede la potestad de participar activamente en las tareas que le eran propias antes de su jubilación, se le da voz en asambleas y reuniones y se le permite asistir en los distintos eventos de la institución en calidad de invitado de honor. La normativa de cada universidad, en cumplimiento del contenido del RDRPU, establecerá los requisitos sine qua non para poder alcanzar esta destacada posición, tras el cumplimiento de la edad legal de jubilación, y seguir manteniendo una vinculación activa con la institución académica. 
La relación laboral contractual es, según el art. 22 RDRPU, de carácter temporal. Ahora bien, no obstante la extinción de la relación contractual, la condición de profesor emérito será vitalicia a efectos honoríficos. En este escenario de privilegios, resulta cuanto menos sorprendente que solo un 20 por ciento de mujeres hayan sido nombradas como profesoras eméritas ${ }^{17}$ en nuestro país y que este dato permanezca inmóvil desde hace casi una década ${ }^{18}$.

A la par de esta cuestión, es oportuno hacer referencia al título de "Doctor Honoris Causa". Se trata de la máxima condecoración que las universidades pueden conceder a profesorado en reconocimiento a su trayectoria en el ámbito académico, científico o cultural, a sus valores y a su especial vinculación con esta institución. También en este caso, compete a cada universidad establecer en su normativa los requisitos que el profesorado debe reunir para presentarse como candidatos/as, siendo las Juntas de Facultad, los Consejos de Departamento o el propio Rectorado los que tienen la potestad de proponer el candidato o candidata a recibir este galardón académico.

Resulta llamativo que solo un 5 por ciento de mujeres haya sido reconocido "por causa de honor" en nuestro país. No parece que el dato relativo al profesorado emérito ni este sea el reflejo de la realidad del mérito, la capacidad, el trabajo, el esfuerzo y la valía del profesorado femenino que conforma la universidad española.

El mayor porcentaje de mujeres 'honoris causa' lo tiene la Universidad de Valencia, con un 10 por ciento, seguida de la Universidad de Alcalá de Henares con un 9 por ciento. Por el contrario, a la cola del ranking de concesiones de esta distinción al profesorado femenino se encuentra la Universidad de Zaragoza, con un 2,4 por ciento. Por último, hay que poner de manifiesto cómo la universidad con más alumnado de España, la Universidad complutense de Madrid, solamente tiene un 3 por ciento de profesoras "honoris causa" lo que evidencia, una vez más la férrea estructura patriarcal de la universidad pública española ${ }^{19}$.

\footnotetext{
${ }^{17}$ EGEA RECHE, Mónica, La igualdad en la educación superior: ¿mito o realidad?, Cuestiones de Género, núm. 1, 2006, págs. 195-203.

${ }^{18}$ INSTITUTO NACIONAL DE ESTADÍSTICA, "Científicas en cifras. Estadísticas e indicadoras de la (des)igualdad de género en la formación y profesión científica", 2013. Según las cifras aportadas en este estudio, solo el $19.5 \%$ de los puestos altos de la carrera científica en la universidad pública lo ocupan mujeres, es decir, esa es la proporción de mujeres que son catedráticas o profesoras eméritas (puestos que reciben la consideración de Grado A en la estandarización internacional de las categorías profesionales para el personal investigador).

${ }^{19} \mathrm{https}$ ://es.blastingnews.com/sociedad/2018/06/el-doctorado-de-honoris-causa-es-otorgado-a-mas-

hombres-que-a-mujeres-002642127.html
} 


\section{LAS UNIDADES DE IGUALDAD DOCE AÑOS DESPUÉS DE LA LOIEMH}

Desde 2007, la LOIEMH trata de eliminar o, al menos, contrarrestar los obstáculos que dificultan la igualdad efectiva entre mujeres y hombres y de fomentar la igualdad plena entre unas y otros como un criterio de calidad del sistema educativo. Más en concreto, en el ámbito de la educación superior, el art. 25 de la citada norma establece que las Administraciones Públicas, en el ejercicio de sus respectivas competencias, fomentarán la enseñanza y la investigación sobre el significado y alcance de la igualdad entre mujeres y hombres, promoviendo la inclusión, en los planes de estudio en que proceda, de enseñanzas en materia de igualdad entre mujeres y hombres, la creación de postgrados específicos y la realización de estudios e investigaciones especializadas en la materia.

En cumplimiento de la LOIEMH, hemos visto cómo la LOU desarrolla a lo largo de su articulado una serie de medidas encaminadas a respetar el principio de igualdad de género. Entre ellas, se establece la creación de una estructura cuyo objetivo primordial sea alcanzar la igualdad real y efectiva entre mujeres y hombres en el ámbito universitario. Su disposición adicional duodécima incluye una nueva exigencia; las universidades contarán entre sus estructuras de organización con unidades de igualdad para el desarrollo de las funciones relacionadas con el principio de igualdad entre hombres y mujeres.

Así las cosas, las unidades de igualdad quedan configuradas como un instrumento de mejora y promoción de la igualdad de género en el seno de las universidades. Desde la entrada en vigor de la LOIEMH, las universidades han ido creando sus respectivas unidades de igualdad de género; sin embargo, no todas las universidades cuentan con una. Asimismo, hay que subrayar que se advierten diferencias importantes en la creación y puesta en funcionamiento de las unidades de igualdad que existen en la actualidad. Este hecho provoca disfunciones en cuanto a sus competencias y poder de cambio.

Así las cosas, conviene detenernos a reflexionar acerca de si el buen o mal funcionamiento de las unidades de igualdad influye de manera relevante en la efectividad del derecho a la igualdad de trato y de oportunidad desde una perspectiva de género. Hacer una comparativa en este sentido de la situación de las tres universidades 
objeto de estudio, nos aportará una visión clara acerca de cómo afecta a la universidad el estado de su unidad de igualdad.

Por ejemplo, en la Universidad de Huelva, la transformación del Vicerrectorado de Planificación Estratégica en otro más amplio denominado "Vicerrectorado de Planificación Estratégica, Calidad e Igualdad" ha sido un hecho trascendental en el diseño de políticas de igualdad entre mujeres y hombres en esta universidad, entre ellas, la valorización y el impulso de su unidad de igualdad.

Hasta julio de 2017, la Unidad de Igualdad y Atención a la Diversidad (UIAD) de la Universidad Huelva se encontraba inserta dentro de los Servicios de Atención a la Comunidad Universitaria (SACU), un órgano de información y asesoramiento al profesorado y, sobre todo, al alumnado en todo tipo de trámites académicos. Sin intención alguna de menospreciar la labor de este organismo, ha sido un acierto incluir la materia de igualdad dentro del vicerrectorado de planificación estratégica, ya que es este un órgano con mayor visibilidad y relevancia dentro de la universidad. Además, el hecho de que se decidiese incluir en este vicerrectorado y no en otro es importante debido a su gran proyección y amplitud; la planificación estratégica es la materia transversal por excelencia dentro de las universidades.

Que la Unidad de Igualdad pase a depender del Vicerrectorado de Planificación Estratégica, Calidad e Igualdad supone que el principio de igualdad de trato y de oportunidades entre mujeres y hombres sea ahora una cuestión central en la estructura de la universidad onubense. Esta metamorfosis ha tenido un impacto directo en este órgano, que ha visto aumentadas sus funciones y también su prestigio. Con la unidad de igualdad, son cinco las unidades que actualmente dependen orgánica y funcionalmente del referido vicerrectorado (planificación estratégica, calidad, igualdad y atención a la diversidad, salud y contabilidad analítica) con una secretaría común. Merece ser destacado que al frente de estas unidades hay 4 mujeres y un hombre, siendo la secretaría también una mujer. La UIAD está redactado su segundo Plan de Igualdad y Protocolo de Acoso.

Tanto la Universidad de Castilla-La Mancha como la de Murcia tienen una situación bien distinta en este sentido. La primera diferencia sustancial en ambos casos con respecto a la Universidad de Huelva es que ni hubo ni hay una persona con plena autonomía que dirija este organismo. 
En la Universidad de Castilla-La Mancha, en un primer momento, la Unidad de Igualdad estuvo ubicada dentro del Vicerrectorado de Cultura, Deportes y Extensión Universitaria y, en la actualidad, forma parte del Vicerrectorado de Estudiantes y Responsabilidad Social. Conviene subrayar cómo la unidad castellanomanchega destinada al cumplimiento del principio de igualdad de trabajo y de oportunidad entre su profesorado ha quedado incluida en el vicerrectorado dedicado a la responsabilidad social universitaria que por definición es voluntaria. Esta realidad tiene su reflejo en la práctica; la Universidad de Castilla-La Mancha no tuvo un Protocolo de Acoso hasta noviembre de 2016 y todavía no ha aprobado un Plan de Igualdad.

Por su parte, la Unidad de Igualdad de la Universidad de Murcia en un principio estuvo vinculada al Vicerrectorado de Responsabilidad Social, Transparencia e Igualdad. Nada más que añadir en relación con el significado que en la práctica tiene incluir la materia de igualdad dentro del vicerrectorado que se encarga de las cuestiones relacionadas con la responsabilidad social. Actualmente, no existe en la Universidad de Murcia este vicerrectorado ni ningún otro con competencias específicas en materia de igualdad, habiendo quedado su Unidad para la Igualdad entre Mujeres y Hombres configurada como un ente propio.

\section{HACIA LA EFECTIVIDAD DE LA IGUALDAD DE OPORTUNIDADES EN EL ÁMBITO UNIVERSITARIO}

El derecho antidiscriminatorio pierde toda razón de ser si no es capaz de combatir la profunda situación de desigualdad que en todos y cada uno de los ámbitos de la sociedad, público y privado, sufre la población femenina. Si las universidades no han corregido en todo este tiempo la baja presencia de las mujeres como lideresas en los órganos de dirección y en los equipos de trabajo, habrá que dar paso a un nuevo modelo que permita que el personal docente e investigador femenino pase de la retaguardia a la vanguardia. Habida cuenta de la situación existente, deviene necesario caminar hacia una nueva organización en el seno de las universidades que posibilite que los espacios de decisión y poder universitarios estén ocupados por hombres y por mujeres de forma proporcional a su presencia, dedicación, capacidades y meritocracia y que eliminen los obstáculos que impiden la promoción profesional de las mujeres en este campo.

De un lado, la aprobación de medidas que contemplen que en los puestos de gestión dominados por hombres se elija a un determinado número de mujeres no parece una 
solución desatinada en el ámbito de la educación superior, habida cuenta de las mejoras que evidencian las normas preceptivas sobre cuotas en empresas en diferentes países de Europa. Trasladar este modelo correctivo a las universidades resulta necesario si se quiere atajar la enorme brecha de género que hemos constatado que existe en el ámbito de la enseñanza superior de nuestro país, donde las mujeres apenas ocupan puestos de responsabilidad, obtienen cátedras, son nombradas como profesoras eméritas o reciben el título "honoris causa".

Este tipo de medidas de acción positiva ${ }^{20}$ deben configurarse como un deber de las empresas públicas $^{21}$ y privadas del que no puede quedar fuera las universidades. El establecimiento de una ley de cuotas en el ámbito de educación superior permitiría que las universidades respetasen al fin una presencia mínima de mujeres en sus órganos colegiados, cumpliéndose así con el principio de igualdad que propugna la Constitución Española y desarrolla, en este campo, la LOU.

De otro, se perfila como imprescindible el diseño de medidas que posibiliten que la maternidad deje de frenar la carrera laboral del PDI femenino, entre las que se encuentran aquellas que apuestan por un reconocimiento positivo de las situaciones de embarazo en los currículums vitae, para que ser madre no sea por más tiempo un 'agujero negro' en la carrera investigadora.

\section{REFERENCIAS BIBLIOGRÁFICAS}

ACKER, S., Género y educación. Reflexiones sociológicas sobre mujeres, enseñanza y feminismo, Narcea, 1995.

BARRÈRE UNZUETA, María Ángeles, Derecho antidiscriminatorio y acción positiva en favor de las mujeres, Civitas, 1997.

EGEA RECHE, Mónica, La igualdad en la educación superior: ¿mito o realidad?, Cuestiones de Género, núm. 1, 2006.

\footnotetext{
${ }^{20}$ ESPEJO MEGÍAS, Patricia, "La necesaria introducción de políticas de género en las universidades españolas", Op. Cit., pág. 301 y ss.

${ }^{21}$ La Ley italiana $\mathrm{n}^{\mathrm{o}}$ 120, de 12 julio de 2011, sobre cuotas de géneros (G.U. 28 julio 2011, n. 174) extendió su ámbito de aplicación en 2012 a las Administraciones Públicas motivo por el cual merece ser puesta en valor y tomada como ejemplo de cambio en el escenario europeo, donde las Universidades y demás organismos públicos adquieren un papel fundamental en el desarrollo social y económico de la ciudadanía.
} 
PATRICIA ESPEJO MEGÍAS Mujeres y Universidad: situación actual y algunas propuestas para el cambio.

ESPEJO MEGIAS, P., Hacia una reformulación de la violencia de género laboral, Wolters Kluwer, 2018.

ESPEJO MEGÍAS, Patricia, "La necesaria introducción de políticas de género en las universidades españolas", en AA.VV. (Coords. CASANOVA MARTÍ, Roser y VILLÓ TRAVÉ, Cristina) Nuevos retos docentes en ciencias sociales y jurídicas, Huygens, 2017.

INSTITUTO NACIONAL DE ESTADÍSTICA, "Científicas en cifras. Estadísticas e indicadoras de la (des)igualdad de género en la formación y profesión científica”, 2013. 